\title{
THIN LAYER CHROMATOGRAPHIC ANALYSIS OF FOOD COLORANTS FROM THREE MORPHOTYPES OF ANNATTO (Bixa orellana L.)
}

\author{
Hari Pada Seal**, Mohammad Amdad Ali ${ }^{*}$, Md. Usuf Ali', Mosammat Hasina Akhter1 \\ and Fowzia Sultana ${ }^{2}$
}

Received 7 December 2011, Revised 20 February 2012, Accepted 15 June 2012, Published online 30 June 2012

\begin{abstract}
This article describes a simple solvent extraction method for the extraction of colorants from the three morphotypes such as, (Morphotype-1 $\left(\mathrm{M}_{1}\right)$, Morphotype-2 $\left(\mathrm{M}_{2}\right)$, and Morphotype$3\left(\mathrm{M}_{3}\right)$ of Annatto (Bixa orellana L.) seeds, and their separation, vivid, and qualitative demonstration by thin-layer chromatography. Several solvent systems (hexane, chloroform, acetone, ethanol, and a mixed-solvent having composition of $\mathrm{CHCl}_{3} / \mathrm{C}_{2} \mathrm{H}_{5} \mathrm{OH} / \mathrm{CH}_{3} \mathrm{COOH}$ (80:2:1)) were applied for extraction of colored components. It was observed that a large portion of colorants was extracted by chloroform. Its effluent was deep brick red in color and transparent. Furthermore, various carrier solvent systems (Benzene-Ethyl acetate) were used to separate the components from the extracts. Carrier solvent system with the ratio of 7:3 was found as superior solvent for chloroform extracts. Three colored-spots were observed for all morphotypes. Among them, the first one was yellow colored having very low polarity and the second and third spots were both redbrick colored having medium and higher polarity respectively. In addition, for $\mathrm{M}_{1}$ no colorless-spot was observed in low and medium polar systems, revealing that the amount of wax and gum were minimum in the extract and superior morphotype among the three.
\end{abstract}

Keywords: Solvent Extraction, Seed Coat, Bixa orellana, Natural Colour, $\mathrm{R}_{\mathrm{f}}$ Value

\footnotetext{
1Department of Agricultural Chemistry, Faculty of Agriculture, Bangladesh Agricultural University, Mymensingh-2202, Bangladesh.

2Department of Poultry Science, Faculty of Animal Husbandry, Bangladesh Agricultural University, Mymensingh-2202, Bangladesh.

*Corresponding author's email: haripadaseal@gmail.com (Hari Pada Seal); amdad53@yahoo.com (Mohammad Amdad Ali)

Reviewed by Dr. Mohammad Gulzarul Aziz, Bangladesh Agricultural University, Mymensingh, Bangladesh.
}

\section{Introduction}

Over the past few decades, it has been a growing concern in worldwide for food quality, safety, and security. Particular attention has been drawn to colorants used in food, drug, cosmetic, and textile industry, where the safety of colorants is one of the most burning issues. While, most of the synthetic colorants tend to be perceived as undesirable and harmful; some are considered to be responsible for allergenic and intolerance reactions (Wissgott and Bortlik, 1996). In contrary, nature-derived products are considered as health friendly and of good quality.

A growing number of natural food colorants are being isolated and excepted to use commercially, such as Caramel coloring (E150) made from caramelized sugar used in cola products and also in cosmetics; Annatto, a reddish-orange dye extracted from the seed of the Bixa orellana L.; Cochineal (E120), a red dye derived from the cochineal insect, Dactylopius coccus; Pandan a green food coloring extracted from Pandanus amaryllifolius; Butterfly pea a blue food dye from Clitoria ternatea. Among them, annatto (E160b) appears as an important one for food and drug industries owing to its potential uses as a substitute of the synthetic colorant Tartrazine which is prohibited in several countries (JECFA, 1982). Annato was classified by the Food and Drug Administration in the U.S.A. as a "color additive exempt of certification" (Hallagan et al., 1995). In addition, this red-orange colorant is extracted from the seeds of Annatto (Bixa orellana L.), can be a potential candidate for replacing the costly "Saffron" which is widely used in medicine, food and cosmetics industry. Annatto tree is frequently seen as an ornamental plant in various parts of the world. It is a tropical tree native to the Central and South American rain forest, and is vastly cultivated in warm regions of the world, such as India, Bangladesh, Sri Lanka, and Java (Wolf, 1997). The dye extracted from the seed coat of the Annatto seeds can be used in coloring cheese, soft drinks, oil, butter, sondesh, vanilla ice-cream, and soap. 
Further, it can be used in some regions to color textiles (Lata et al., 1990) and color fabrics and weapons (Rao et al., 2002). Recently, Ali (2006) reported three morphotypes of Annatto namely, morphotype-1 $\left(\mathrm{M}_{1}\right)$, morphotype-2 $\left(\mathrm{M}_{2}\right)$, and morphotype-3 $\left(\mathrm{M}_{3}\right)$ were found in Bangladesh.

Here we reported qualitative assessment of three morphotypes of Annatto in order to develop a simple inexpensive process for extracting the colorants.

\section{Materials and Methods}

\section{Extraction of colorants}

The matured-fruit-capsule of Annatto (Bixa orellana L.) of three morphotypes: morphotype-1 $\left(\mathrm{M}_{1}\right)$, morphotype $2\left(\mathrm{M}_{2}\right)$, and morphotype-3 $\left(\mathrm{M}_{3}\right)$ were collected from Botanical Garden of Bangladesh Agricultural University (BAU). The fruit-capsules were dried in sunlight for 30 hours and seeds were separated out from the capsules. After that, the seeds were dried in sunlight for another 30 hours and preserved in a refrigerator at $20^{\circ} \mathrm{C}$ for further analysis. To extract the colorants, $100 \mathrm{~g}$ of seeds were soaked in $200 \mathrm{ml}$ particular organic solvent for 30 minutes and stirred abrasively by a glass rod for one hour (Islam, 2008). Extracting solvents were selected based on their polarity, viz. hexane (Polarity: 0), chloroform (Polarity: 4.1), acetone (Polarity: 5.1), and ethanol (Polarity: 5.2) (Finar, 2000). In addition, a mixed-solvent system of $\mathrm{CHCl}_{3} / \mathrm{C}_{2} \mathrm{H}_{5} \mathrm{OH} / \mathrm{CH}_{3} \mathrm{COOH} \quad(80: 2: 1)$ also was employed. Finally, it was filtered by Whatman Grade-114 filter paper to prepare the stock solution for Thin Layer Chromatographic (TLC) analysis.

\section{Thin layer chromatography analysis of colorants}

The chromoplate were prepared by dispersing a suspension of finely powdered silica gel adsorbent (50 $\mathrm{g}$ silica gel thoroughly mixed and swelled in $125 \mathrm{ml}$ of water) on a glass strip (EMerck India limited, Mumbai, 400018) of suitable size ( $5 \mathrm{~cm} \times$ $1 \mathrm{~cm} \times 0.3 \mathrm{~cm})$. A very thin uniform layer of silica was formed on glass strip with the aid of a spreader. It was then dried in an oven at $105 \pm 5^{\circ} \mathrm{C}$ for 12 hours. For obtaining a chromatogram, the chromoplate was spotted with a minute drop of annatto extract with the help of a capillary tube, and then placed vertically in a solvent tank. Development of the chromatogram occurred by capillary movement of the solvent up the silicaadsorbent layer. When solvent front reached at the upper end of the TLC plate, it was marked and the plate was taken out and allowed to dry. If the components were colored, then the spots were readily located. To ascertain the presence of colorless spots, the TLC plate was transferred to iodine chamber. Both colored and colourless spots on the TLC plate were recorded and $R_{f}$ values were calculated. The $R_{f}$ value depends on the relative polarities of the carrier solvent and spotcomponents. It is defined as the ratio of the distance travelled by a component to the distance travelled by the solvent front (Finar, 2000). $R_{f}$ value indicates the polarity of the spot-components in the TLC plate (Saraswathy et al., 2004). Similar polarities of carrier solvent and spot-components leading higher $R_{f}$ value and vice-verse.

\section{Results and Discussion}

\section{Extraction of colorant}

Colorants were extracted from the three morphotypes of Annatto seeds by employing variety of solvents (hexane, chloroform, acetone, ethanol, and a mixed solvent system), shown in Table 1. Solvents were selected based on their polarity to find out the suitable solvent for extracting the colorants. The hexane extracted effluent was transparent; however, the intensity of color was very light, indicating that only components of low polarities were extracted by hexane. When chloroform was employed, the effluent solution was very transparent and deep red brick color, shown in Fig. 1 and Table 1, suggesting that chloroform is one of the suitable solvents to extract the colorants. Furthermore, the colorants extracted by more polar solvents such as, acetone and ethanol were dark and cloudy, like emulsion. It might be due to some undesired highly polar components were also extracted along with the colorants. In addition, mixed solvents extracted effluent was transparent and brick red color, indicating that it is only selective to brick red colored pigments (Saraswathy et al., 2004).

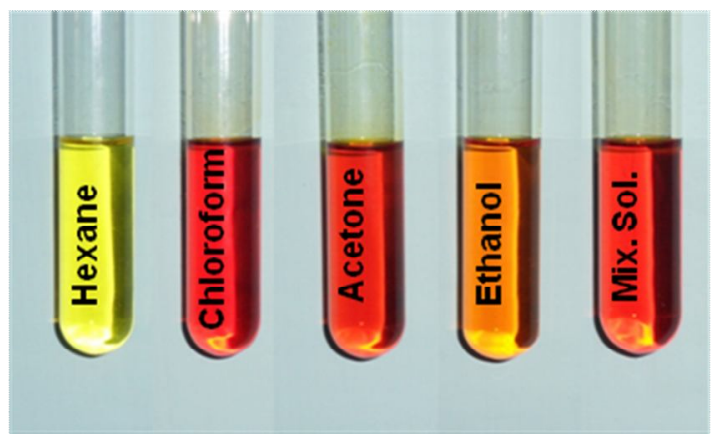

Fig. 1. Colorants extracts by solvents

\section{Thin layer chromatographic analysis of colorant}

To separate and evaluate the coloring pigments from the solvent extracted effluents, TLC was employed. Both colored and colorless spots and their $R_{f}$ values were recorded (Finar, 2000; Saraswathy et al., 2004). 
Table 1. Physical properties of colorant extracts

\begin{tabular}{lllll}
\hline $\begin{array}{l}\text { Extracting } \\
\text { solvent }\end{array}$ & Polarity & Color/Intensity & Transparency & Inferences \\
\hline Hexane & 0.0 & Yellow/ Light & Transparent & Suitable for non-polar dyes \\
Chloroform & 4.1 & Brick red/Deep & Transparent & Suitable \\
Acetone & 5.1 & Amber/Dark & Cloudy & Not suitable \\
Ethanol & 5.2 & Orange/ Dark & Cloudy & Not suitable \\
Mixed solvent & - & Amber/Light & Transparent & $\begin{array}{l}\text { Suitable for selected } \\
\text { colorants }\end{array}$ \\
\hline
\end{tabular}

\section{Hexane extracts}

Table 2 shows the $\mathrm{R}_{\mathrm{f}}$ values of both colored and colorless spots of $n$-hexane extracts. The starting carrier solvent was benzene (100\%), in this case, colored-spots were not developed regardless of three morphotypes. However, after exposing in $\mathrm{I}_{2}$ vapor, $\mathrm{M}_{1}$ and $\mathrm{M}_{2}$ showed few spots, attributing for the colorless compounds. When mixed solvent systems of benzene/ ethyl acetate (Bz/EtOAc) with the ratio of $3: 2,7: 3$, and 4:1 were employed, respectively, $\mathrm{M}_{1}$ as well as $\mathrm{M}_{3}$ showed one colored spot respectively and no colorless spot was observed, indicating that they were exclusion of colorless compounds (gum, wax, etc.). In case of $\mathrm{M}_{2}$, two colored spots were seen: first one was yellow in color with low $R_{f}$ value, and second one was brick red in color with higher $R_{f}$ value respectively. It suggested that both low and high polar pigments (i.e. yellow and brick red colored constituents respectively) were present in the hexane extracted annatto. After exposing to $\mathrm{I}_{2}$ vapor, few spots were also observed. On the basis of colored and colorless spots, and their $R_{f}$ values, it can be concluded that Bz/ EtOAc (3:2) and (7:3) solvent mixture were the superior carrier solvents for $\mathrm{M}_{1}$ and $\mathrm{M}_{3}$ morphotypes.

Table 2. TLC analysis of hexane extracted colorants

\begin{tabular}{cccc}
\hline \multirow{2}{*}{ Morphotype } & \multirow{2}{*}{ Eluting solvent } & \multicolumn{2}{c}{ Value of $\mathrm{R}_{\mathrm{f}}$} \\
\cline { 3 - 4 } $\mathrm{M}_{1}$ & & Colored spot & Colorless spot \\
& & - & 0.416 \\
$\mathrm{M}_{2}$ & $\mathrm{Bz}=100 \%$ & - & 0.602 \\
& & - & 0.504 \\
$\mathrm{M}_{3}$ & & 0.113 & 0.416 \\
$\mathrm{M}_{1}$ & & 0.939 & - \\
$\mathrm{M}_{2}$ & $\mathrm{Bz} / \mathrm{EtOAC}=3: 2$ & 0.173 & - \\
$\mathrm{M}_{3}$ & & 0.156 & 0.965 \\
$\mathrm{M}_{1}$ & & 0.084 & - \\
$\mathrm{M}_{2}$ & $\mathrm{Bz} / \mathrm{EtOAC}=7: 3$ & 0.940 & - \\
$\mathrm{M}_{3}$ & & 0.110 & 0.983 \\
$\mathrm{M}_{1}$ & & 0.067 & 0.840 \\
$\mathrm{M}_{2}$ & $\mathrm{Bz} / \mathrm{EtOAc}=4: 1$ & 0.940 & - \\
$\mathrm{M}_{3}$ & & 0.060 & 0.983 \\
\hline & & 0.949 & 0.967 \\
\hline
\end{tabular}

\section{Chloroform extracts}

Solvent systems of Bz/ EtOAc with the ratio of 1:0, 9:1, 7:3, 1:1, and 0:1 were exploited separately as carrier solvent, presented in Table 3. Bz (100\%) provided single color spot for all the morphotypes. After transferring to $\mathrm{I}_{2}$ chamber, only $\mathrm{M}_{2}$ showed two spots. In case of solvent systems 9:1 and 7:3, three colored spots were observed for all morphotypes. Among them, the first one was yellow colored spot with very low polarity and the second spot was red color with moderate polarity and the third one was brick red color. Most of the cases for $\mathrm{M}_{1}$ and $\mathrm{M}_{3}$ colorless spots were not appeared, suggesting that colorless compounds were absent in these morphotypes. These two carrier solvent systems seemed to be suitable solvent for separating the dyes from the chloroform extract. Further increasing in portion of EtOAc, as in case of 1:1 and EtOAc (100\%), both color and colorless spots were observed.

\section{Acetone extracts}

Table 4 shows the $R_{\mathrm{f}}$ values for chromatogram of acetone extracts. Similar trend was observed in using $\mathrm{Bz}$ (100\%); only colorless components were present. 
Table 3. TLC analysis of chloroform extracted colorants

\begin{tabular}{|c|c|c|c|}
\hline \multirow{2}{*}{ Morphotype } & \multirow{2}{*}{ Eluting solvent } & \multicolumn{2}{|c|}{ Value of $R_{f}$} \\
\hline & & Colored spot & Colorless spot \\
\hline $\mathrm{M}_{1}$ & \multirow{3}{*}{ Bz (100 \%) } & 0.235 & - \\
\hline $\mathrm{M}_{2}$ & & 0.227 & 0.504 \\
\hline $\mathrm{M}_{3}$ & & 0.219 & $\begin{array}{c}0.090 \\
-\end{array}$ \\
\hline \multirow[b]{2}{*}{$\mathrm{M}_{1}$} & \multirow{8}{*}{$\mathrm{Bz} / \mathrm{EtOAc}=9: 1$} & 0.983 & \\
\hline & & $\begin{array}{l}0.845 \\
0.128\end{array}$ & - \\
\hline \multirow{4}{*}{$\mathrm{M}_{2}$} & & 0.990 & 0.983 \\
\hline & & 0.846 & 0.957 \\
\hline & & 0.213 & 0.897 \\
\hline & & 0.957 & \\
\hline \multirow[t]{2}{*}{$\mathrm{M}_{3}$} & & 0.803 & - \\
\hline & & 0.128 & \\
\hline \multirow{3}{*}{$\mathrm{M}_{1}$} & \multirow{9}{*}{$\mathrm{Bz} / \mathrm{EtOAc}=7: 3$} & 0.929 & \\
\hline & & 0.835 & - \\
\hline & & 0.144 & \\
\hline \multirow{4}{*}{$\mathrm{M}_{2}$} & & 0.945 & \\
\hline & & 0.850 & 0.910 \\
\hline & & 0.236 & \\
\hline & & 0.958 & \\
\hline \multirow[t]{2}{*}{$\mathrm{M}_{3}$} & & 0.883 & 0.983 \\
\hline & & 0.166 & \\
\hline $\mathrm{M}_{1}$ & \multirow{5}{*}{$\mathrm{Bz} / \mathrm{EtOAc}=1: 1$} & 0.140 & - \\
\hline & & 0.932 & 0.907 \\
\hline $\mathrm{M}_{2}$ & & 0.210 & 0.974 \\
\hline \multirow{2}{*}{$\mathrm{M}_{3}$} & & 0.924 & \\
\hline & & 0.180 & - \\
\hline $\mathrm{M}_{1}$ & \multirow{4}{*}{ EtOAc (100\%) } & 0.122 & - \\
\hline \multirow[t]{2}{*}{$\mathrm{M}_{2}$} & & 0.967 & 0.934 \\
\hline & & 0.131 & \\
\hline $\mathrm{M}_{3}$ & & $\begin{array}{c}0.959 \\
0.114\end{array}$ & 0.943 \\
\hline
\end{tabular}

Table 4. TLC analysis of acetone extracted colorants

\begin{tabular}{|c|c|c|c|}
\hline \multirow{2}{*}{ Morphotype } & \multirow{2}{*}{ Eluting solvent } & \multicolumn{2}{|c|}{ Value of $R_{f}$} \\
\hline & & Colored spot & Colorless spot \\
\hline $\mathrm{M}_{1}$ & & - & - \\
\hline & & & 0.983 \\
\hline $\mathrm{M}_{2}$ & Bz (100 \%) & - & 0.459 \\
\hline $\mathrm{M}_{3}$ & & _ & \\
\hline $\mathrm{M}_{1}$ & & 0.949 & 0.983 \\
\hline & & 0.168 & 0.967 \\
\hline $\mathrm{M}_{2}$ & $\mathrm{Bz} / \mathrm{EtOAc}=9: 1$ & 0.957 & 0.967 \\
\hline $\mathrm{M}_{3}$ & & 0.210 & - \\
\hline $\mathrm{M}_{1}$ & & 0.084 & _ \\
\hline & & 0.924 & 0.983 \\
\hline $\mathrm{M}_{2}$ & $\mathrm{Bz} / \mathrm{EtOAc}=7: 3$ & 0.101 & 0.840 \\
\hline $\mathrm{M}_{3}$ & & 0.067 & - \\
\hline $\mathrm{M}_{1}$ & & 0.14 & - \\
\hline $\mathrm{M}_{2}$ & & 0.932 & 0.974 \\
\hline & Bz/ EtOAc $=1: 1$ & 0.210 & 0.907 \\
\hline $\mathrm{M}_{3}$ & & $\begin{array}{l}0.924 \\
0.180\end{array}$ & - \\
\hline
\end{tabular}


While mixed solvents were employed, one/ two colored spots were developed. Between them one was very low polarity with yellow colored spot and other was brick red with moderate polarity. $\mathrm{M}_{2}$ provided two colorless spots; however, $\mathrm{M}_{1}$ and $\mathrm{M}_{3}$ did not showed any spot under iodine vapor. On depending of the colored and colorless spots, and their $R_{f}$ values, it seemed that Bz/EtOAc (9:1) solvent system was the superior carrier solvent for separating dyes from acetone extracts. In this case, TLC chromatogram of $\mathrm{M}_{1}$ and $\mathrm{M}_{2}$ showed two colored spots, and its $\mathrm{R}_{\mathrm{f}}$ value was 0.949 and 0.168 for $M_{1}$; and 0.957 and 0.176 for $M_{2}$, respectively. For the $\mathrm{M}_{3}$, one colored spot was appeared with $R_{f}$ of 0.210 and did not show any spots under iodine vapor.

Table 5. TLC analysis of ethanol extracted colorants

\section{Ethanol extracts}

For developing the chromatogram of ethanol extract, $\mathrm{Bz}(100 \%)$ and mixture of Bz/EtOAc were used as carrier solvent, shown in Table 5. As excepted, Bz did not carry any color components. With the inclusion of EtOAc, in 7:3 and 6.5:3.5 ratios two colored spots were observed for all the morphotypes. Between them one was yellow color with very low polarity and the second spot was brick red color. After exposing to iodine vapor, one spot was appeared for all morphotypes. Further increasing the portion of EtOAc, i.e., in 6:4, only single color spot was seen for all the morphotypes.

\begin{tabular}{cccc}
\hline Morphotype & Eluting solvent & Colored spot & Value of $\mathrm{R}_{\mathrm{f}}$ \\
\cline { 3 - 4 } $\mathrm{M}_{1}$ & & - & Colorless spots \\
$\mathrm{M}_{2}$ & $\mathrm{Bz}(100 \%)$ & - & 0.50 \\
$\mathrm{M}_{3}$ & & - & 0.528 \\
$\mathrm{M}_{1}$ & & 0.983 & - \\
$\mathrm{M}_{2}$ & \multirow{3}{*}{$\mathrm{Bz} /$ EtOAc $=7: 3$} & 0.122 & 0.959 \\
$\mathrm{M}_{3}$ & & 0.983 & 0.959 \\
$\mathrm{M}_{1}$ & & 0.914 & 0.959 \\
$\mathrm{M}_{2}$ & \multirow{3}{*}{ Bz/ EtOAc $=6.5: 3.5$} & 0.098 & 0.967 \\
$\mathrm{M}_{3}$ & & 0.975 & 0.967 \\
$\mathrm{M}_{1}$ & \multirow{2}{*}{$\mathrm{Bz} / \mathrm{EtOAc}=6: 4$} & 0.983 & 0.967 \\
$\mathrm{M}_{2}$ & & 0.190 & - \\
$\mathrm{M}_{3}$ & & 0.983 & - \\
\hline
\end{tabular}

Considering these chromatograms, it seemed that $\mathrm{Bz} / \mathrm{EtOAc}$ with the ratio of 6:4 solvent system can be used for separating selective dye. Its chromatogram indicated that $\mathrm{M}_{1} \mathrm{M}_{2}$, and $\mathrm{M}_{3}$ contained one colored spots with $\mathrm{Rf}$ value of $0.459,0.475$, and 0.508 , respectively.

\section{Mixed-solvent of chloroform/ethanol/ acetic acid (80:2:1) extracts}

Table 6 shows the $R_{f}$ values of colored and colorless spots of mixed solvents extract; and $\mathrm{Bz} /$ EtOAc solvent systems were attempted to separate the components. In every case, only Table 6. TLC analysis of mixed-solvents extracted colorants

\begin{tabular}{cccc}
\hline Morphotype & \multirow{2}{*}{ Eluting solvent } & \multicolumn{3}{c}{ Value of $\mathrm{R}_{\mathrm{f}}$} \\
\cline { 3 - 4 } & & Colored spot & Colorless spots \\
\hline $\mathrm{M}_{1}$ & \multirow{3}{*}{$\mathrm{Bz}(100 \%)$} & 0.104 & - \\
$\mathrm{M}_{2}$ & & 0.104 & - \\
$\mathrm{M}_{3}$ & & 0.104 & - \\
$\mathrm{M}_{1}$ & \multirow{2}{*}{$\mathrm{Bz} / \mathrm{EtOAC}=9: 1$} & 0.295 & - \\
$\mathrm{M}_{2}$ & & 0.305 & - \\
$\mathrm{M}_{3}$ & & 0.315 & - \\
$\mathrm{M}_{1}$ & \multirow{2}{*}{$\mathrm{Bz} / \mathrm{EtOAC}=7: 3$} & 0.184 & - \\
$\mathrm{M}_{2}$ & & 0.193 & - \\
$\mathrm{M}_{3}$ & & 0.202 & - \\
$\mathrm{M}_{1}$ & \multirow{2}{*}{$\mathrm{Bz} / \mathrm{EtOAC}=1: 1$} & 0.809 & - \\
$\mathrm{M}_{2}$ & & 0.826 & - \\
$\mathrm{M}_{3}$ & & 0.843 & \\
\hline
\end{tabular}

colored spots were observed in chromatogram and it was brick red color having high polarity, suggesting that extracts of mixed solvent comprised of mostly colored constituents. On the basis of separation of colored and colorless spots, and their $\mathrm{R}_{\mathrm{f}}$ values; it may be concluded that Bz/EtOAc (1:1) solvent mixture was most suitable carrier solvent for separating the dyes from the extract of mixed solvent systems. In all case, $\mathrm{M}_{1}, \mathrm{M}_{2}$, and $\mathrm{M}_{3}$ developed only one colored spot respectively and, their $\mathrm{R}_{\mathrm{f}}$ value were 0.809 for $\mathrm{M}_{1}, 0.826$ for $\mathrm{M}_{2}$ and 0.843 for $\mathrm{M}_{3}$. 


\section{Conclusion}

Three coloring constituents in each morphotypes $\left(\mathrm{M}_{1}, \mathrm{M}_{2}\right.$, and $\left.\mathrm{M}_{3}\right)$ of Annatto were observed. Among the three pigments, one was associated with high $R_{f}$ value, i.e., very low polarity and yellow in color. The rest of the two pigments were brick red and orange colored associated with medium and low $\mathrm{R}_{\mathrm{f}}$ value, respectively. Moreover, after exposing in iodine vapor, most of the chromatogram indicated the presence of colorless components. Studies from $\mathrm{R}_{\mathrm{f}}$ values of colorless components revealing that one was low polar colourless components and other two colorless compounds were of medium polarity. Furthermore, chloroform extract effluent was very deep brick red in color and transparent. On depending of the chromatogram, mixed solvent systems of Bz/EtOAc of 7:3 was superior carrier solvent for separating the dyes from the chloroform extracts. Thus, dyes separated from the extract can be used in coloring the food, medicine, cosmetic and other purpose.

\section{References}

Ali, M. 2006. Morphological variation in Bixa orellana. MS Thesis. Dept. Crop Bot., Bangladesh Agril. Univ., Mymensingh-2202, Bangladesh. 44p.

Finar, I.L. 2000. Organic Chemistry. Volume 2: Stereochemistry and the chemistry of Natural Products. pp. 79-80.

Hallagan, J.B., Allen, D.C. and Borzelleca, J.F. 1995. The Safety and Regulatory Status of
Food, Drug and Cosmetics Colour Additives Exempt from Certification. Food Chem. Toxicol., 33(6): 515-528.

Islam, S. 2008. Flower and capsule production in relation to dye yield in Bixa orellana. MS Thesis. Dep. Crop Bot., Agric. Univ., Mymensingh, Bangladesh. 40p.

JECFA. 1982. Evaluation of Certain Food Additives and Contaminants; Twenty-Sixth Report of the Joint FAP/WHO Expert Committee on Food Additives; Technical Report Series No. 683; WHO: Geneva. 51p.

Lata, R., Aparnathi, K.D. and Sharma, R.S. 1990. Annatto (Bixa orellana L.), its cultivation, preparation and usage. Int. J. Trop. Agric., 8 (1): 80-88.

Rao, P.G.P., Satyanarayana, A. and Rao, D.G. 2002. Effect of Storage on the Stability of Water Soluble Annatto Dye Formulation in a Simulated Orange-RTS Beverage Model System. Lebensmittel Wissenschaft and Technologic, 35 (7): 617-621.

Saraswathy, S., Manavalan, R.S.A., Vadivcl, E., Manian, K. and Subramanian, S. 2004. Influence of various extraction methods on dye yield in annatto (Bixa orellana. L). South Indian Hort., 52(1/6): 239-243.

Wissgott, U. and Bortlik, K. 1996. Prospects for New Natural Food Colorants. Trends Food Sci. Technol. 7: 298-302.

Wolf,M.A.1997.http:// home. Braunschweig. Netsurf. Deandree. Wolf/ urucum. Html. 